\title{
Analysis of Interwell Connectivity of Tracer Monitoring in Carbonate Fracture-Vuggy Reservoir: Taking T-Well Group of Tahe Oilfield as an Example
}

\author{
Shuyao Sheng $\mathbb{D}$, Yonggang Duan $(\mathbb{D}$, Mingqiang Wei $\mathbb{D}$, Tao Yue, Zijian Wu, \\ and Linjiang Tan \\ School of Petroleum Engineering, Southwest Petroleum University, Chengdu 610500, China \\ Correspondence should be addressed to Yonggang Duan; nanchongdyg@163.com
}

Received 24 February 2021; Accepted 17 June 2021; Published 31 July 2021

Academic Editor: Chao Zhang

Copyright (C) 2021 Shuyao Sheng et al. This is an open access article distributed under the Creative Commons Attribution License, which permits unrestricted use, distribution, and reproduction in any medium, provided the original work is properly cited.

\begin{abstract}
Carbonate fracture-vuggy reservoirs are one of the hot spots in oil and gas exploration and development. However, it is extremely difficult to describe the internal spatial structure of the fracture-vuggy unit and understand the interwell connection relationship. As a method to measure reservoir characteristics and feedback reservoir production information directly according to the detected concentration curve, interwell tracer technology provides a direct measure for people to understand the law of oil-water movement and reservoir heterogeneity and is widely used in various domestic oil fields. Based on the flow law of tracer and the CFD flow simulation basic model, this paper establishes the physical conceptual model and studies the influence of three physical parameters (the flow velocity of the fluid passing through the connected channel, diameter of the connected channel, and length of the connected channel) on the concentration curve at the outlet. In addition, the influence of different interwell connection modes on tracer concentration was studied and classified scientifically. According to the simulation, the tracer concentration curve can be classified into three types: unimodal curve, bimodal curve, and multimodal curve. Finally, the injection-production well group in the T-well area of the Tahe Oilfield is taken as an example, the connection mode between injection and production wells in this well area is further discussed and has been verified, which can be used as a reference for the connectivity analysis of similar carbonate reservoirs.
\end{abstract}

\section{Introduction}

Carbonate reservoirs are one of the most important areas of oil and gas exploration and development in the world $[1,2]$. Its reserves account for $52 \%$ of the world's proven reserves, and the extracted oil production accounts for $60 \%$ of the world. Among them, the development reserves of carbonate fractured-vuggy low-permeability reservoirs in western China account for as high as 70\%, which is the main force for increasing oil reserves and production. Therefore, studying the development of this type of reservoirs has become a top priority, especially the study of their connectivity [3]. Accurate interpretation of the reservoir connectivity pattern from injector to producer is critical to the success of the improved oil recovery (IOR). However, due to the geological heterogeneity and structural complexity of carbonate fractured-vuggy lowpermeability reservoirs, accurate interwell evaluation may be very challenging [4].

There are many methods to analyze the connectivity between injectors and producers. In the early days, a large number of traditional methods emerged, such as the geochemical method [5, 6], interference well test analysis method [7-9], interwell data analysis method [10-12], and interwell data modeling method [13-22]. Although these methods are practical and convenient, the implementation process will affect the normal production of the oil field, and the low accuracy of the analysis results greatly compromises the availability of these methods. As the research progresses, numerical simulation methods specifically aimed at analyzing the interwell connectivity were being widely used. Zhang et al. [23] used 
reservoir numerical simulation technology to estimate the connectivity between oil wells and water injection wells in low-permeability microfracture reservoirs. This method can accurately estimate the location and velocity of the waterflood front, the permeability of fractures, the seepage flow situation of reservoir, the production performance of the reservoir, and main and secondary flow channels, etc. Zhao et al. [24] proposed the Interwell Numerical Simulation Model (INSIM), which has less computational effort than before and could be used as a calculation tool to obtain the reservoir performance under waterflooding conditions. The reservoir numerical simulation method can quantitatively evaluate the connectivity and its dynamic changes, but it is time-consuming and complex to build the model, although there are other types of methods to analyze interwell connectivity, such as $4 \mathrm{D}$-seismic data method [25], bottom-hole-temperature data method [26], and neural network(NN) method [27]. Due to the high cost of seismic surveys, high requirements for temperature monitors, and tedious calculation steps of a neural network, these methods cannot perfectly solve the problems of the oil field. For these reasons, the tracer method has become a better choice.

Tracer technology was applied in hydrology to monitor groundwater movement in the early 1900s. The application of the tracer technology in the petroleum industry did not begin until nearly half a century later [28]. In oilfields, the information obtained by tracer technology is reliable, unambiguous, and definitive, and thus, it helps to reduce uncertainty about flow paths, reservoir continuity, and reservoir directional characteristics. This method only needs less equipment and instruments to get the test results, which greatly reduces the cost and has high accuracy. Nowadays, tracer technology has developed more maturely. There have been many cases of interwell tracer monitoring used in oil fields [29-33]. The research of tracer monitoring used in fractured carbonate reservoirs generally prefers chemicals [34] or combines dynamic surveillance data with new analytical tools $[35,36]$. However, the study of tracer interwell monitoring also has certain limitations. The quantitative response of interwell tracer tests was discussed by Hagoort in 1982 [37]. The discussion included the calculation of the response to the injection of a tracer pulse, the influence of tracer mixing, and the numerical simulation of field tracer tests. Although quantitative analysis was proposed earlier, it has been seldom used. Most tracer tests have been used in a rather qualitative manner.

In this paper, a further discussion is carried out on the tracer concentration diffusion formula, and the software simulation method is used to analyze the tracer concentration curve affected by different formula parameters and different model shapes. To improve the reliability of the results, this paper is based on the test data of an oilfield. The Ordovician oil reservoir of Tahe Oilfield is the largest carbonate fractured-vuggy reservoir ever found in China [38]. However, there are relatively few studies on connectivity in this oilfield block, and interwell connectivity is also discussed in traditional ways [39, 40]. Therefore, the characteristics of tracer concentration curves of monitoring wells are studied and scientifically classified by taking the injection-production well group in the carbonate fracture-type T-well area of Tahe Oilfield as an example. The connection mode between injection and production wells in the T-well area is discussed, which can be used for the reference for the connectivity analysis of carbonate fracture-vuggy reservoirs of the same type.

\section{Methodology}

2.1. Physical Model. The Ordovician of the Tarim Basin in the Tahe Oilfield is a typical carbonate fractured-vuggy reservoir. We have collected the FMI (formation microscanner image) logging curve (see Figure 1(a)) of this characteristic reservoir. It can be seen from the curve that the large dark patches are connected with the long dark shadows. These features indicate the existence of large karst-type caves or fracture-cavity aggregates in the reservoir. In addition, the thin slice image of the cave and the carved image of the carbonate fracturevuggy reservoir body can also verify the above conclusions (see Figures 1(b) and 1(c)). In summary, these characteristics all show that the large caves in the reservoir are connected by percolation channels with high permeability. Therefore, this paper will use the above conclusions as a basis for the establishment of the model.

The initial model is established as shown in Figure 2. The connected channel in Figure 2 simulates the interwell connected channel between the injection well and the production well in the carbonate fractured-vuggy low-permeability reservoirs. The parameter values of the model are shown in Table 1.

2.2. Methodology for the Flow Law of Tracer. The principle of tracer monitoring is to track synchronously by simultaneously injecting the water and tracer. After the tracer is injected with water, its flow is mainly affected by convection and diffusion. Convection is based on Darcy's law, and the fluid reaches the flow state through the pressure gradient generated between injection-production wells. The diffusion is composed of the molecular diffusion caused by the difference of fluid concentration and the mechanical dispersion caused by the heterogeneity of porous media. Because of the influence of dispersion, the tracer is no longer limited to convection caused by pressure difference but extends to the water channeling layer, and the concentration display will also show peak characteristics. Tracer monitoring in oil fields obtains such concentration curves with peak shape characteristics and analyzes and uses them. Therefore, it is urgent to explore methods to study the peak pattern of tracer concentration.

During the detection process, the hydrodynamic dispersion equation when the tracer is injected instantaneously is as follows [41]:

$$
\frac{\partial c}{\partial t}=D \frac{\partial^{2} c}{\partial l^{2}}-u \frac{\partial c}{\partial l}
$$

The boundary condition of Equation (1) is

$$
\begin{cases}c(l, 0)=0, & l \geq 0, \\ c(0, \mathrm{t})=c_{0}, & t \geq 0, \\ \lim _{l \longrightarrow \infty} c(l, t)=0, & t>0 .\end{cases}
$$



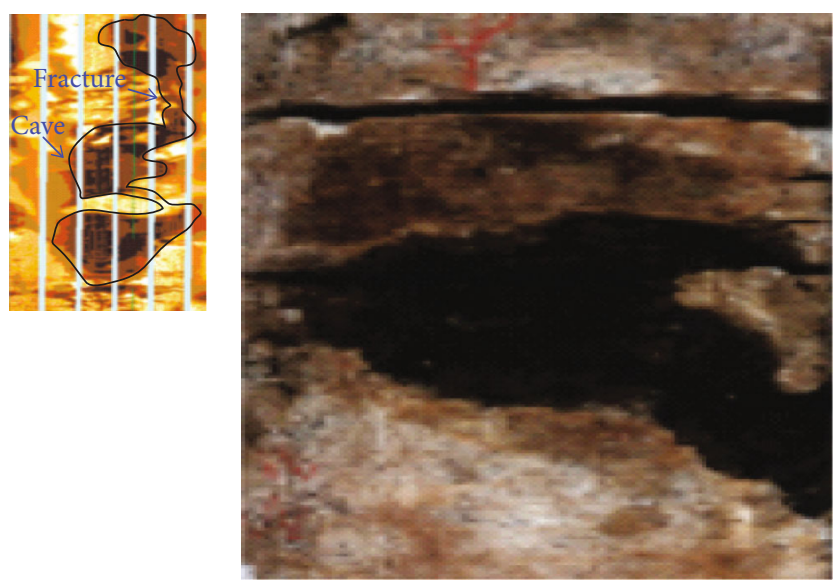

(a)

(b)

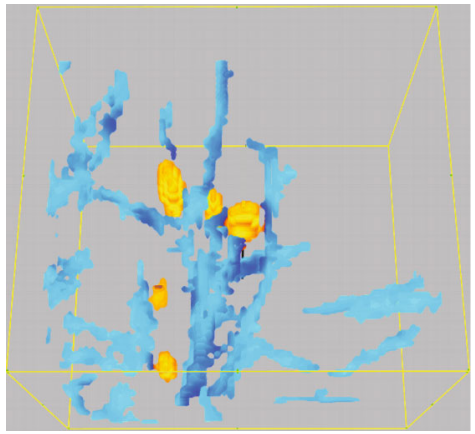

Fractured-vuggy reservoir

Well

(c)

FIGURE 1: Proof of connecting channel in the carbonate fractured-vuggy reservoir. (a) FMI logging curve; (b) well test curve; (c) carving of carbonate fracture-vuggy reservoir body.

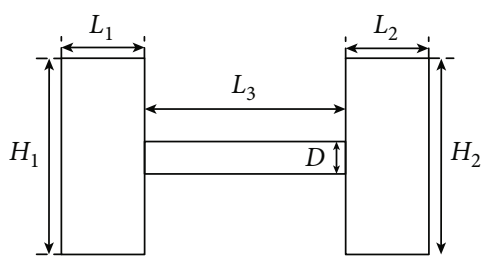

(a)

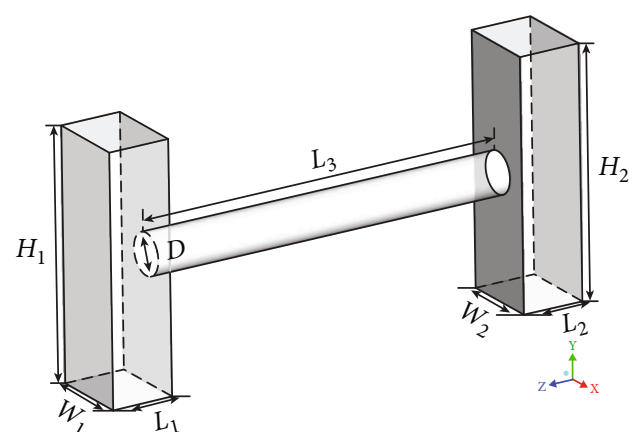

(b)

Figure 2: Schematic of the initial model: (a) 2D; (b) 3D.

Thus, Equation (1) can be solved and simplified as

$$
c(l, t)=\frac{c_{0}}{2} \operatorname{erfc}\left(\frac{l-u t}{\sqrt{4 D t}}\right),
$$

where $c$ is the tracer concentration and $c_{0}$ is the initial concentration of the tracer, $t$ is the tracer migration time, $D$ is the diffusion coefficient, $l$ is the tracer migration distance, and $u$ is the flow velocity.

However, the length of the tracer slug in the flow tube is far less than the length of the flow tube. Therefore, Equation (3) can be rewritten as 
TABLE 1: The parameter values of the model.

\begin{tabular}{lcc}
\hline Symbol & Parameters & Value \\
\hline$L_{1}$ & Inlet length $(\mathrm{mm})$ & 15 \\
$L_{2}$ & Outlet length $(\mathrm{mm})$ & 15 \\
$L_{3}$ & Connected channel length $(\mathrm{mm})$ & 90 \\
$H_{1}$ & Inlet height $(\mathrm{mm})$ & 60 \\
$H_{2}$ & Outlet height $(\mathrm{mm})$ & 60 \\
$W_{1}$ & Inlet width $(\mathrm{mm})$ & 20 \\
$W_{2}$ & Outlet width $(\mathrm{mm})$ & 20 \\
$D$ & Connected channel diameter $(\mathrm{mm})$ & 10 \\
\hline
\end{tabular}

$$
c(l, t)=\frac{L c_{0}}{\sqrt{4 \pi D t}} \exp \left[-\frac{(l-u t)^{2}}{4 D t}\right] .
$$

The injected tracer slug size, $L$, is defined as

$$
L=\frac{4 V}{\pi d^{2}} .
$$

The concentration equation of the tracer at any position in the flow tube is

$$
c(l, t)=\frac{2 V c_{0}}{\pi d^{2} \sqrt{\pi D t}} \exp \left[-\frac{(l-u t)^{2}}{4 D t}\right],
$$

where $V$ is the volume of the injected tracer slug and $d$ is the diameter of the migration channel.

According to Equation (6), the concentration change curve of the tracer dispersion theoretically (in a stable flow) should show a normal distribution, which is a bisymmetrical unimodal curve. However, in the actual situation, the production concentration of tracer is affected by various parameters such as channel length and liquid flow velocity. Therefore, to explore these laws clearly separately, the CFD simulation tool is used here to carry out actual flow simulation research.

2.3. Methodology for CFD Flow Simulation Basic Model. To visually explore the migration law of the tracer fluid in different seepage channels, the CFD (Computational Fluid Dynamics) method should be used for research [42]. Its core principle is to numerically solve the differential equations that control the fluid flow; the discrete distribution of the flow field in a continuous area can be obtained to approximate the fluid flow. The law of physical conservation (law of conservation of mass, law of conservation of momentum, and law of conservation of energy) is the essence of the CFD method. The three law equations are shown in Equations $((7)-(9))$ :

$$
\frac{\partial \rho}{\partial t}+\frac{\partial\left(\rho u_{x}\right)}{\partial x}+\frac{\partial\left(\rho u_{y}\right)}{\partial y}+\frac{\partial\left(\rho u_{z}\right)}{\partial z}=0
$$

where $\rho$ is the fluid density, $t$ is time, and $u_{x} \backslash u_{y} \backslash u_{z}$ is the velocity component on the $x \backslash y \backslash z$ axes, respectively.

$$
\begin{aligned}
& \frac{\partial\left(\rho u_{x}\right)}{\partial t}+\nabla \cdot\left(\rho u_{x} u\right)=-\frac{\partial p}{\partial x}+\frac{\partial \tau_{x x}}{\partial x}+\frac{\partial \tau_{y x}}{\partial y}+\frac{\partial \tau_{z x}}{\partial z}+\rho f_{x}, \\
& \frac{\partial\left(\rho u_{y}\right)}{\partial t}+\nabla \cdot\left(\rho u_{y} u\right)=-\frac{\partial p}{\partial y}+\frac{\partial \tau_{x y}}{\partial x}+\frac{\partial \tau_{y y}}{\partial y}+\frac{\partial \tau_{z y}}{\partial z}+\rho f_{y}, \\
& \frac{\partial\left(\rho u_{z}\right)}{\partial t}+\nabla \cdot\left(\rho u_{z} u\right)=-\frac{\partial p}{\partial z}+\frac{\partial \tau_{x z}}{\partial x}+\frac{\partial \tau_{y z}}{\partial y}+\frac{\partial \tau_{z z}}{\partial z}+\rho f_{z},
\end{aligned}
$$

where $p$ is the pressure on the fluid microelement body; $\tau_{x x}, \tau_{x y}$, and $\tau_{x z}$ are the components of the viscous stress tensor on the surface of the fluid microelement body; and $f_{x}, f_{y}$, and $f_{z}$ are the components of the mass force on the $x, y$, and $z$ axes of the fluid per unit mass, respectively.

$$
\begin{aligned}
\frac{\partial(\rho T)}{\partial t}+ & \frac{\partial\left(\rho u_{x} T\right)}{\partial x}+\frac{\partial\left(\rho u_{y} T\right)}{\partial y}+\frac{\partial\left(\rho u_{z} T\right)}{\partial z} \\
& =\frac{\partial}{\partial x}\left(\frac{\alpha}{c_{p}} \frac{\partial T}{\partial x}\right)+\frac{\partial}{\partial y}\left(\frac{\alpha}{c_{p}} \frac{\partial T}{\partial y}\right)+\frac{\partial}{\partial z}\left(\frac{\alpha}{c_{p}} \frac{\partial T}{\partial z}\right)+S_{T}
\end{aligned}
$$

where $T$ is the temperature, $c_{p}$ is the specific heat capacity, $\alpha$ is the fluid heat transfer coefficient, and $S_{T}$ is the viscous dissipation term.

On the premise of observing the law of conservation, the turbulence model selected for the tracer fluid simulation in this paper is the standard $k-\varepsilon$ model, which is an empirical model based on the turbulence energy equation and the diffusion rate equation:

$$
\begin{gathered}
\rho \frac{d k}{d t}=\frac{\partial}{\partial x_{i}}\left[\left(\mu+\frac{\mu_{t}}{\sigma_{k}}\right) \frac{\partial k}{\partial x_{i}}\right]+G_{k}+G_{b}-\rho \varepsilon-Y_{M}, \\
\rho \frac{d \varepsilon}{d t}=\frac{\partial}{\partial x_{i}}\left[\left(\mu+\frac{\mu_{t}}{\sigma_{\varepsilon}}\right) \frac{\partial \varepsilon}{\partial x_{i}}\right]+C_{1 \varepsilon} \frac{\varepsilon}{k}\left(G_{k}+C_{3 \varepsilon} G_{b}\right)-C_{2 \varepsilon} \rho \frac{\varepsilon^{2}}{k}, \\
\mu_{t}=\rho C_{\mu} \frac{k^{2}}{\varepsilon},
\end{gathered}
$$

where $k$ is the turbulent kinetic energy; $\varepsilon$ is the turbulent dissipation rate; $\mu_{t}$ is the turbulent viscosity coefficient; $G_{k}$ is the turbulent kinetic energy caused by the average velocity gradient; $G_{b}$ is the turbulent kinetic energy caused by buoyancy; $Y_{M}$ is the influence of compressible turbulent pulsating expansion on total dissipation rate; $C_{\mu}$ is a constant, $0.09 ; \sigma_{k}$ is a constant, $1.0 ; \sigma_{\varepsilon}$ is a constant, $1.3 ; C_{1 \varepsilon}$ is a constant, 1.44; $C_{2 \varepsilon}$ is a constant, 1.92 ; and $C_{3 \varepsilon}$ is a constant, 0.09 .

The essence of the method of solving the above partial differential equation is to be able to use the iterative method to solve the discretized algebraic equation cyclically to obtain the convergent solution of the equations. In 1972, Patankar 
and Spalding [43] proposed a semi-implicit method for solving pressure coupling equations, namely, the SIMPLE algorithm. This method can correct the pressure field on the basis of the discrete grid, calculate the velocity field to check whether it converges, and finally obtain a convergent solution through repeated corrections and inspections.

In this paper, the FEM software is selected as the CFD simulation tool for actual flow simulation research. A conceptual model with connected channels between injectionproduction wells was established. The inlet (on the side of the injection-production well) was set as a constant injection velocity and injected a mixture of ordinary liquid and special tracer liquid. The outlet (on the side of the production well) is the location where the liquid flows out. By setting the monitoring surface at the outlet, the variation of the concentration of the surface with the time step can be obtained. According to Equation (6), by changing some of the parameters in the equation or changing the shape of the physical model, different kinds of the concentration curves of the tracer can be drawn and then classified and discussed.

\section{Results}

3.1. Influence of Model Parameters on Tracer Concentration Curve. This section is based on the physical model established in Section 2.1. The inlet is set to flow into the tracer mixture and the outlet to flow out. The simulation streamline diagram of the model is shown in Figure 3.

According to the established initial physical model and combined with Equation (6), the three typical parameters of fluid flow velocity $u$, connected channel diameter $d$, and channel length $l$ are selected for analysis. Each parameter value of the model is changed by using the control variable method. The variation of the concentration curve at the outlet of the model with each parameter can be observed and studied.

3.1.1. Different Fluid Flow Velocity. To study the influence of the interwell fluid flow velocity ( $u$ in Equation (6)) on the tracer concentration curve, a single connected channel model is adopted, as shown in Figure 2. The basic parameters of the model in Table 1 are kept unchanged, and only the injection velocity at the inlet is changed to $0.05 \mathrm{~m} / \mathrm{s}, 0.1 \mathrm{~m} / \mathrm{s}$, and 0.15 $\mathrm{m} / \mathrm{s}$. The results are discussed below.

It can be analyzed from Figure 4(a) that the faster the fluid flow velocity, the greater the tracer concentration, the smaller the peak area of the concentration graph, the higher the peak, and the earlier the concentration breakthrough time.

3.1.2. Different Connected Channel Diameter. To study the influence of the interwell connected channel diameter $(d$ in Equation (6)) on the tracer concentration curve, a single connected channel model is adopted, as shown in Figure 2. Set the fluid flow velocity at the inlet to $0.15 \mathrm{~m} / \mathrm{s}$. The other basic parameters of the model in Table 1 are kept unchanged, and only the connected channel diameter is changed to $8 \mathrm{~mm}$, $10 \mathrm{~mm}$, and $12 \mathrm{~mm}$. The results are discussed, respectively.

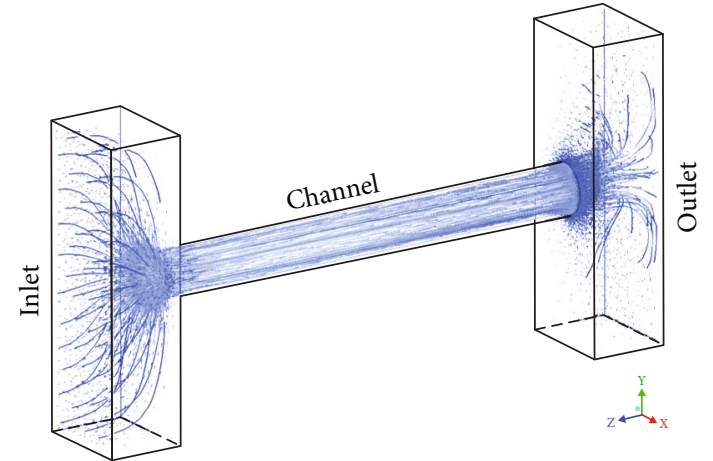

FIgURE 3: Schematic diagram of the model simulation streamline. Dense streamlines refer to high fluid flow, and sparse streamlines refer to low fluid flow.

It can be analyzed from Figure 4(b) that the larger the diameter of the connected channel in the model, the smaller the tracer concentration, the smaller the peak area of the concentration graph, and the lower the peak. However, these changes are not obvious.

3.1.3. Different Connected Channel Length. To study the influence of the interwell connected channel length ( $l$ in Equation (6)) on the tracer concentration curve, a single connected channel model is adopted, as shown in Figure 2. Set the fluid flow velocity at the inlet to $0.15 \mathrm{~m} / \mathrm{s}$. The other basic parameters of the model in Table 1 are kept unchanged, and only the connected channel length is changed to $60 \mathrm{~mm}$, $90 \mathrm{~mm}$, and $120 \mathrm{~mm}$. The results are discussed, respectively.

It can be analyzed from Figure 4(c) that the longer the length of the connected channel in the model, the smaller the tracer concentration, the smaller the peak area of the concentration graph, the lower the peak, and the later the concentration breakthrough time.

In summary, when the flow velocity of the fluid passing through the connected channel decreases, the diameter and length of the connected channel increase, and the tracer concentration changes with a decreasing trend. Moreover, the flow velocity and the length of the connected channel also affect the breakthrough time of the tracer concentration curve. The summary is shown in Table 2 .

However, not only is it the inherent physical parameters of these models that influence the change of the resulting tracer concentration curve but also the shape of the connected channel determines the shape of the tracer concentration curve. There are many types and complex relationships of interwell connected channels in carbonate fracturedvuggy low-permeability reservoirs, so it is urgent to study the influence of different interwell connection modes on the tracer concentration curve shape.

3.2. Influence of Interwell Connection Mode on Tracer Concentration Curve. To further study the influence of the interwell connectivity mode on tracer concentration, different connectivity models were established by using FEM software's preprocessing module. The flow velocity here is set to 


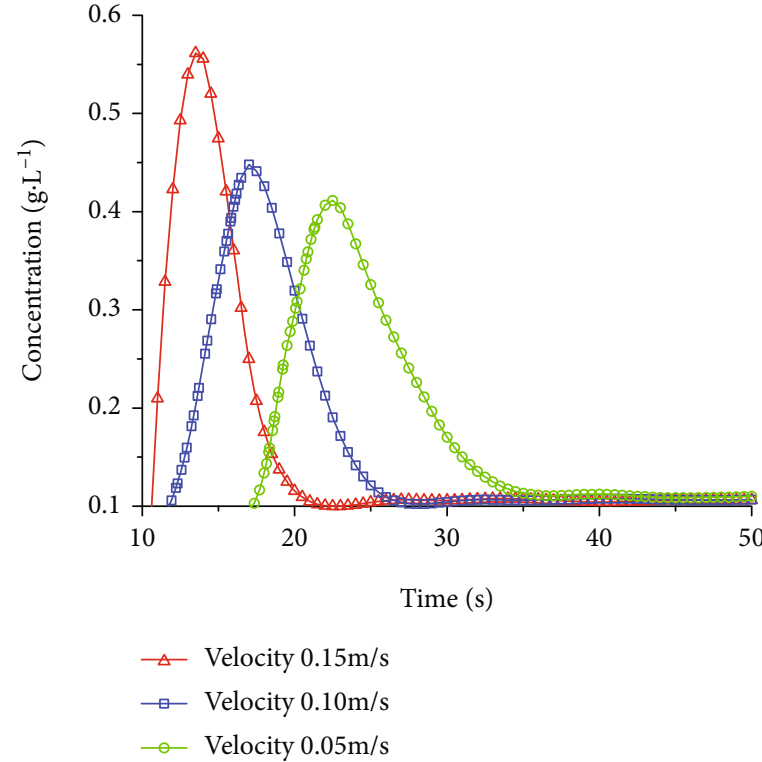

(a)

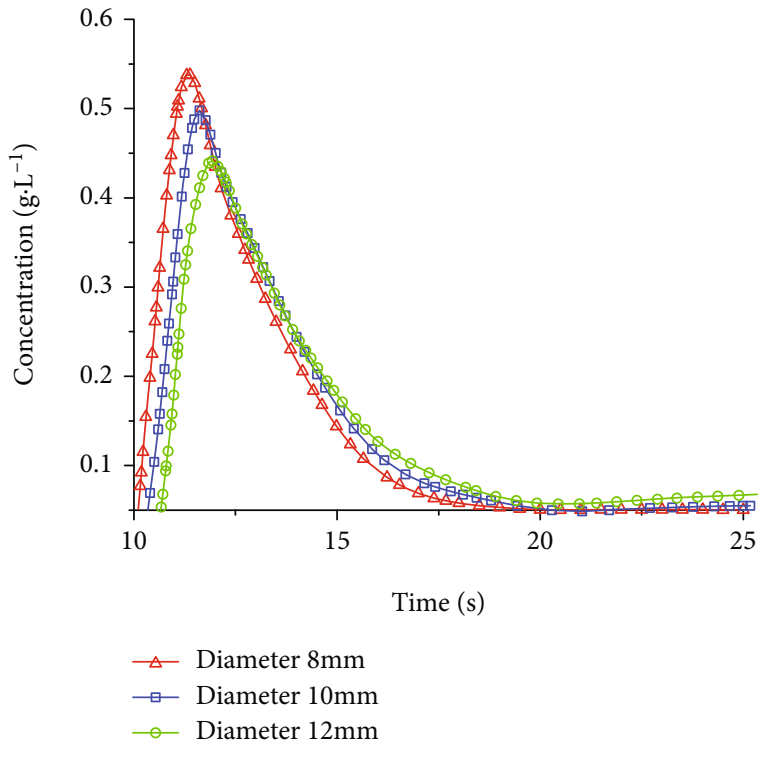

(b)

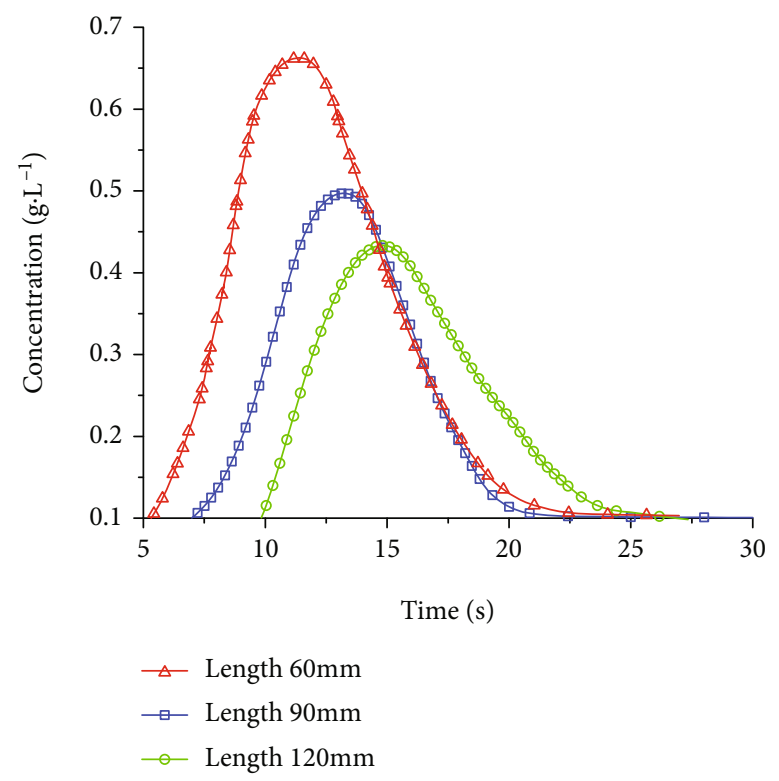

(c)

FiguRE 4: Influence of model parameters on tracer concentration curve: (a) different fluid flow velocity; (b) different connected channel diameter; (c) different connected channel length.

TABLE 2: Sensitivity analysis and summary of each parameter.

Conclusion

Fluid flow velocity

Velocity $\uparrow$, tracer concentration $\uparrow$, the peak $\uparrow$, the peak area of the concentration graph $\downarrow$

Connected channel diameter Connected channel diameter $\uparrow$, tracer concentration $\downarrow$, the peak $\downarrow$, the peak area of the concentration graph $\downarrow$ Connected channel length $\quad$ Connected channel length $\uparrow$, tracer concentration $\downarrow$, the peak $\downarrow$, the peak area of the concentration graph $\downarrow$ 


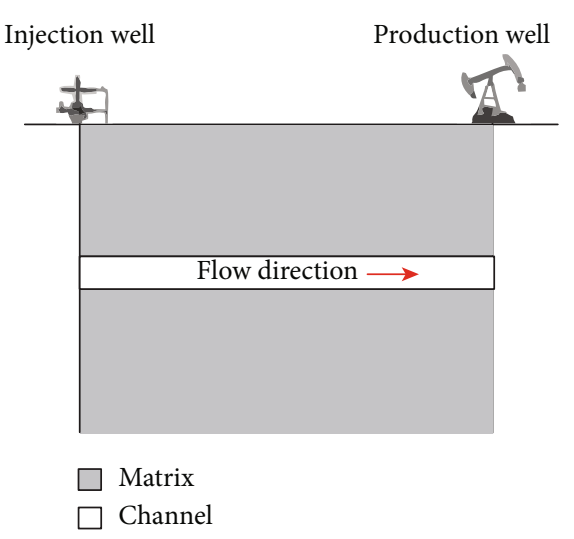

(a)

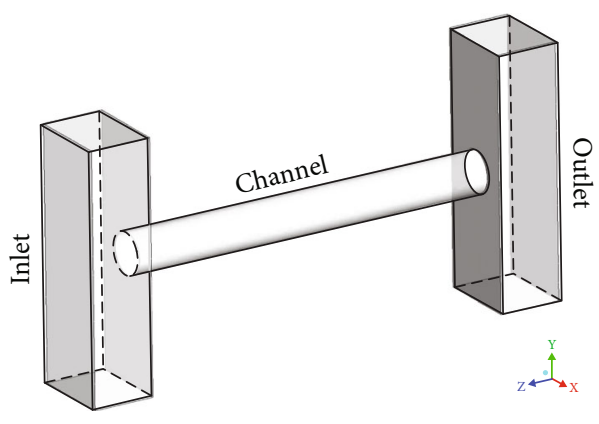

(b)

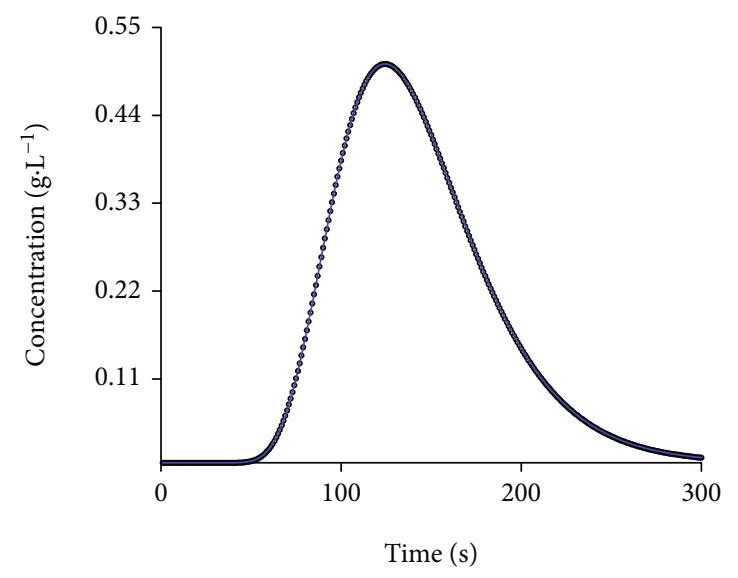

(c)

FIGURE 5: Schematic diagram and model of interwell connected channel and tracer concentration curve (steep unimodal curve): (a) 2D; (b) 3D; (c) tracer concentration change at the outlet.

$0.8 \mathrm{~m} / \mathrm{s}$. The length of the connected channel is fixed at 90 $\mathrm{mm}$, and only the style of the connected channel is changed. The simulation results of different connected models are classified and discussed. According to the characteristics of the tracer concentration curve results, the curve types can be divided into 4 major categories, and different types reflect different interwell connections.

3.2.1. Unimodal Curve. As shown in Figures 5 and 6 , the tracer concentration curve presents a single peak shape, with a steep unimodal curve and a gentle unimodal curve. The steep unimodal curve shows that the tracer concentration curve has a large slope, reflecting that there is only a single small-volume connecting channel between injection-production wells and no other channel. Limited dispersion is the main reason for the rapid change of tracer concentration. The gentle unimodal curve shows the small slope of the tracer concentration curve, reflecting the single large-volume connecting channel between the injection and production wells. The great dispersion caused the slow change rate of tracer concentration.

3.2.2. Bimodal Curve. As shown in Figure 7, the tracer concentration curve presents a double peak shape. The bimodal curve shows that the concentration of the tracer has the curvilinear characteristics of a two-stage wave peak. It reflects that the injection and production wells are connected through two connecting channels, and the volume of the two connecting channels affects the peak value of the tracer concentration curve and the rate of concentration change. A part of the fluid with the tracer will inevitably flow to the production well first through the channel with low resistance, which is the reason for the inconsistency of the arrival time on the concentration curve.

3.2.3. Multimodal Curve. As shown in Figure 8, the tracer concentration curve shows the shape of multiple peaks. The multimodal curve shows that the tracer concentration has multiple peaks and the peaks vary in height. It reflects that there are multiple connecting channels between injection-production wells, which is a combination mode of large-volume connected channels and small-volume connected channels. Figure 8 shows three connecting channels between injectionproduction wells. In view of the difference in the size of the connected channels, the time and height of the peak of the tracer concentration curve were also slightly different. The reason for the inconsistency of the arrival time on the concentration curve is the same as that in Section 3.2.2.

The analysis and summary are shown in Table 3. 


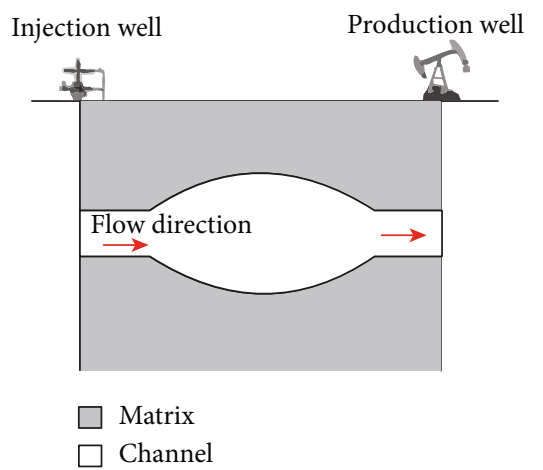

(a)

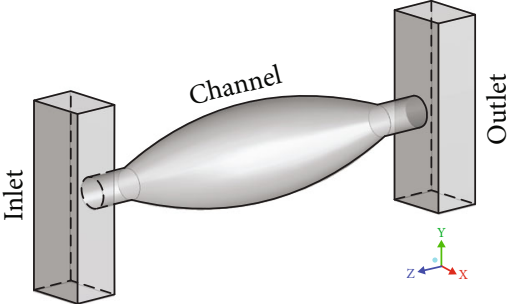

(b)

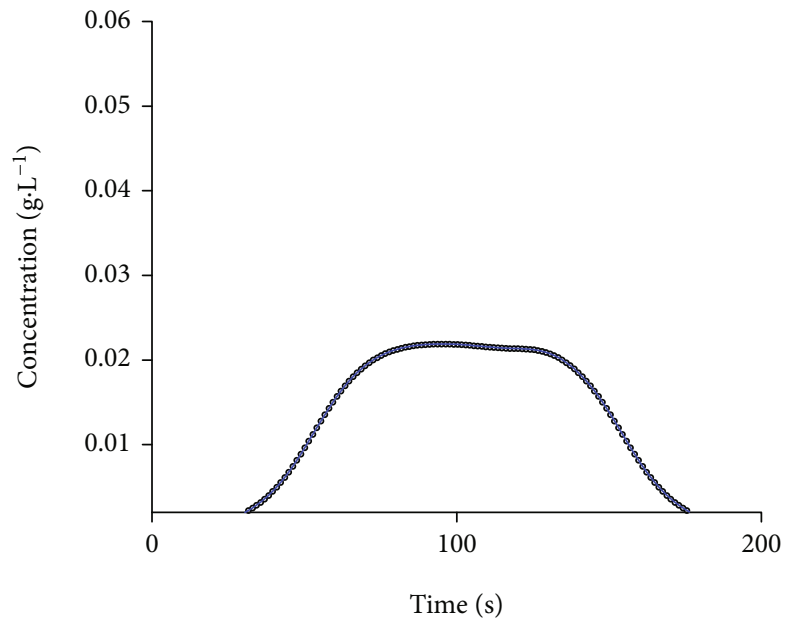

(c)

FIGURE 6: Schematic diagram and model of the interwell connected channel and tracer concentration curve (gentle unimodal curve): (a) 2D; (b) 3D; (c) tracer concentration change at the outlet.

Because the data obtained from field sampling in oilfields is generally related to tracer fluorescence intensity and time, it is necessary to seek the linear relationship between tracer solution concentration and fluorescence intensity. As follows,

$$
F=2.303 \cdot \phi_{f} \cdot I_{0} \cdot E \cdot b \cdot C_{m}
$$

In the case of fixed determination conditions, the fluorescence intensity of the tracer solution is in direct proportion to its concentration:

$$
F=K C_{m}
$$

where $F$ is the fluorescence intensity, $I_{0}$ is the intensity of incident light, $\phi_{f}$ is the fluorescence quantum efficiency, $E$ is the absorption coefficient, $C_{m}$ is the mass concentration of the substance, and $K$ is the direct proportionality coefficient.

Based on the above conclusions, according to the classification of the interconnection methods between wells researched by different curve shapes, the monitoring results of the tracer at the Tahe site can be classified, analyzed, and discussed.

\section{Analysis of Example Wells in Tahe Oilfield}

4.1. Overview of Well Groups. The tectonic location of Tahe Oilfield belongs to the southwest of the Akkule uplift in the middle part of the Shaya uplift in Tarim Basin. The west of Akkule uplift is the Harahatang depression, the east is the Caohu depression, the south is the Mangal depression, and the north is the Yakra fault convex. The reservoir is a carbonate rock karst fracture-vuggy-type reservoir, which is controlled by tectonic faults and multistage karst on the basis of the reservoir and formed by multiset fracture-vuggy system superposed in three-dimensional space. The storage space is dominated by karst caves. The relationship between oil and water in the reservoir is complex, controlled by different fracture and hole systems, and there is locally trapped water and active bottom water.

To judge the connection relationship of the wells in the unit and provide a basis for the adjustment of injection and production parameters of the unit in the later stage of water injection, the tracer was added during the water injection period of the T826 well, and samples from its six adjacent wells were used as tracer monitoring. There are 3 venting wells in this group of monitoring wells: T705 lost well section: 6104.21-6207 m, a total of $209.2 \mathrm{~m}^{3}$ of lost mud; T826 lost well section: $5779.56-5788.07 \mathrm{~m}$, a total of $166.6 \mathrm{~m}^{3}$ of lost 


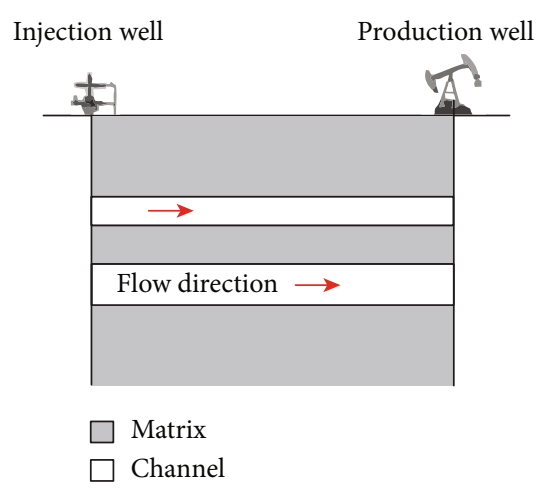

(a)

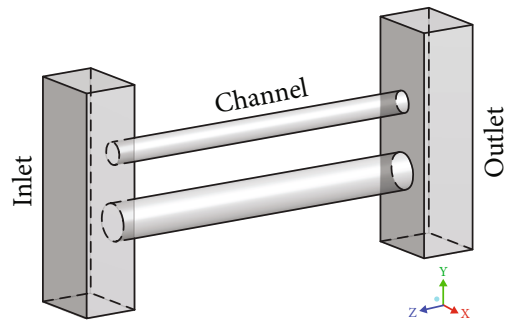

(b)

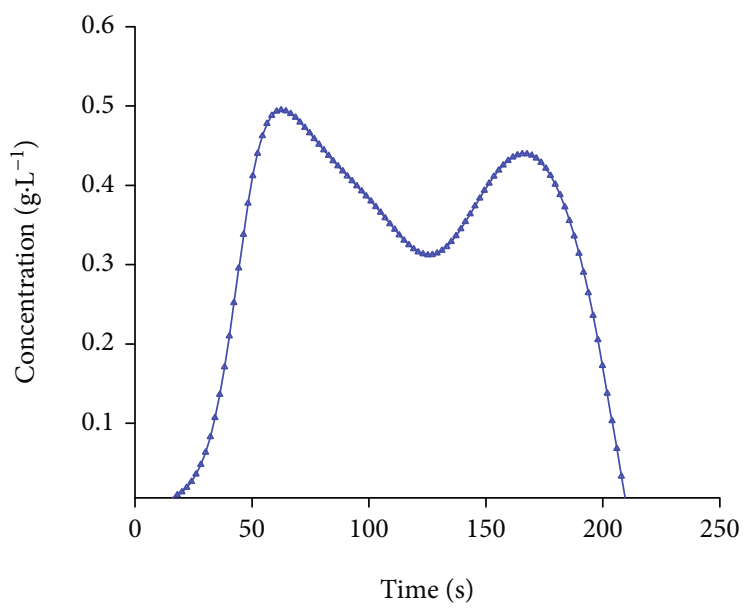

(c)

FIGURE 7: Schematic diagram and model of interwell connected channel and tracer concentration curve (bimodal curve): (a) 2D; (b) 3D; (c) tracer concentration change at the outlet.

mud; and T849 lost well section: 5819.00-5822.51 m, a total of $561 \mathrm{~m}^{3}$ of lost mud.

4.2. Calculation of Injection Volume of Tracer. To enable the oilfield injection and production wells to monitor the tracer normally, it is usually necessary to determine the maximum dilution concentration of the tracer first to avoid problems such as failure to monitor and analyze. According to the formula of maximum average dilution volume,

$$
\begin{gathered}
V_{p}=\pi R^{2} \cdot H \cdot C \cdot \phi \cdot N \cdot S_{w} \cdot a \cdot \lambda \\
\lambda=1+\frac{\sum_{1}^{n}\left(h_{1}+h_{2}+\cdots+h_{n-1}+h_{n}\right)}{\sum_{1}^{n}\left(H_{1}+H_{2}+\cdots+H_{n-1}+H_{n}\right)}+\frac{\sum_{1}^{n}\left(q_{1}+q_{2}+\cdots+q_{n-1}+q_{n}\right)}{V_{\max }},
\end{gathered}
$$

where $V_{p}$ is the maximum dilution volume of the tracer, $R$ is the average well distance between the water injection well and each production well, $H$ is the average reservoir thickness, $C$ is the constant water absorption thickness coefficient, $\phi$ is the porosity, $N$ is the reservoir shape coefficient, $S_{w}$ is the water saturation, $a$ is the water injection sweep coefficient, $\lambda$ is the hole coefficient, $h_{1} \cdots h_{n}$ is the leakage section of the monitoring well, $H_{1} \cdots H_{n}$ is the production section of the monitoring well, $n$ is the number of monitoring wells, $q$ is the leakage of the monitoring well, and $V_{\max }$ is the maximum dilution volume of the monitoring well.

Using Equation (17) and Table 4, the dosage of the tracer can be calculated as $18 \mathrm{~kg}$.

$$
A=S \cdot V_{p} \cdot \mu,
$$

where $A$ is the dosage of the tracer, $S$ is the detection sensitivity of the tracer, and $\mu$ is the margin coefficient.

After determining the dosage of the tracer used in Well T826, the injection parameters of the well group should be optimized (see Table 5). The injection pressure should be close to the injection pressure before the tracer is injected or higher than the original water injection pressure.

4.3. Analysis of Tracer Test Results. By sorting out the tracer monitoring data of the six adjacent wells in the T-Well Group of Tahe, the tracer fluorescence intensity (FI) curve obtained can be summarized according to the classification in Section 3.2 as shown in Table 6.

Combined with the results of the previous exploration, the comprehensive curve analysis, and Equation (14), the 


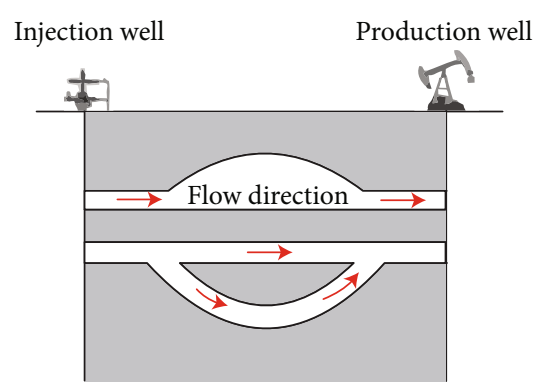

Matrix

Channel

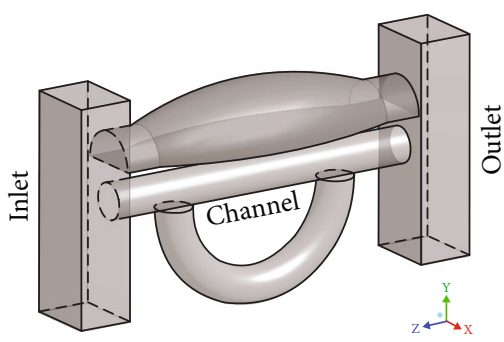

(b)

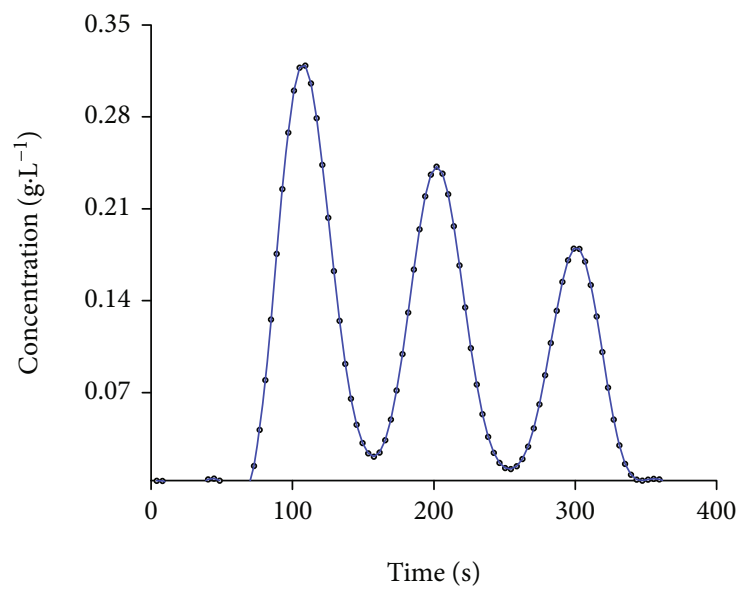

(c)

FIGURE 8: Schematic diagram and model of interwell connected channel and tracer concentration curve (multimodal curve): (a) 2D; (b) 3D; (c) tracer concentration change at the outlet.

TABLE 3: Summary of tracer concentration curve characteristics of each model.

\begin{tabular}{lc}
\hline Characteristics of the model & Characteristics of tracer concentration curve \\
\hline Single small-volume connecting channel & The steep unimodal curve \\
Single large-volume connecting channel & The gentle unimodal curve \\
Two connecting channels & Bimodal curve \\
Multiple connecting channels & Multimodal curve \\
\hline
\end{tabular}

TABLE 4: Calculation table of the maximum dilution volume of tracer.

\begin{tabular}{|c|c|c|c|c|c|c|c|c|c|}
\hline \multicolumn{10}{|c|}{ Parameter } \\
\hline $\begin{array}{l}\text { Well } \\
\text { group }\end{array}$ & $\begin{array}{c}\text { Reservoir } \\
\text { shape } \\
\text { factor }\end{array}$ & $\begin{array}{l}\text { Average } \\
\text { reservoir } \\
\text { radius }(\mathrm{m})\end{array}$ & $\begin{array}{l}\text { Average } \\
\text { reservoir } \\
\text { thickness } \\
\quad(\mathrm{m})\end{array}$ & $\begin{array}{c}\text { Equal water } \\
\text { absorption } \\
\text { thickness } \\
\text { coefficient }\end{array}$ & $\begin{array}{c}\text { Average } \\
\text { reservoir } \\
\text { porosity }(\%)\end{array}$ & $\begin{array}{c}\text { Water } \\
\text { saturation } \\
(\%)\end{array}$ & $\begin{array}{c}\text { Sweep } \\
\text { coefficient of } \\
\text { water } \\
\text { injection }\end{array}$ & $\begin{array}{l}\text { Coefficient } \\
\text { of the hole }\end{array}$ & $\begin{array}{l}\text { Maximum } \\
\text { dilution } \\
\text { volume of } \\
\text { tracer } \\
\left(\times 10^{4} \mathrm{~m}^{3}\right)\end{array}$ \\
\hline T826 & 0.5 & 1647.4 & 58.4 & 0.3 & 0.3 & 0.55 & 0.35 & 1.2 & 517.33 \\
\hline
\end{tabular}

TABLE 5: Optimization table of each parameter of tracer injection.

\begin{tabular}{lcccccc}
\hline $\begin{array}{l}\text { Well } \\
\text { number }\end{array}$ & Tracer type & $\begin{array}{c}\text { Tracer dosage } \\
(\mathrm{kg})\end{array}$ & $\begin{array}{c}\text { Preparation } \\
\text { concentration }(\%)\end{array}$ & $\begin{array}{c}\text { Operating pipe } \\
\text { string }\end{array}$ & $\begin{array}{c}\text { Injection pressure } \\
(\mathrm{MPa})\end{array}$ & $\begin{array}{c}\text { Dosing amount of } \\
\text { tracer }(\mathrm{L})\end{array}$ \\
\hline T826 & $\begin{array}{c}\text { Fluorescent } \\
\text { tracer }\end{array}$ & 18 & 100 & $\begin{array}{c}\text { The original } \\
\text { string }\end{array}$ & $\begin{array}{c}\text { Water injection } \\
\text { pressure }\end{array}$ & 18 \\
\hline
\end{tabular}


TABLE 6: Classification table of tracer fluorescence intensity curve in monitoring wells of T-Well Group.

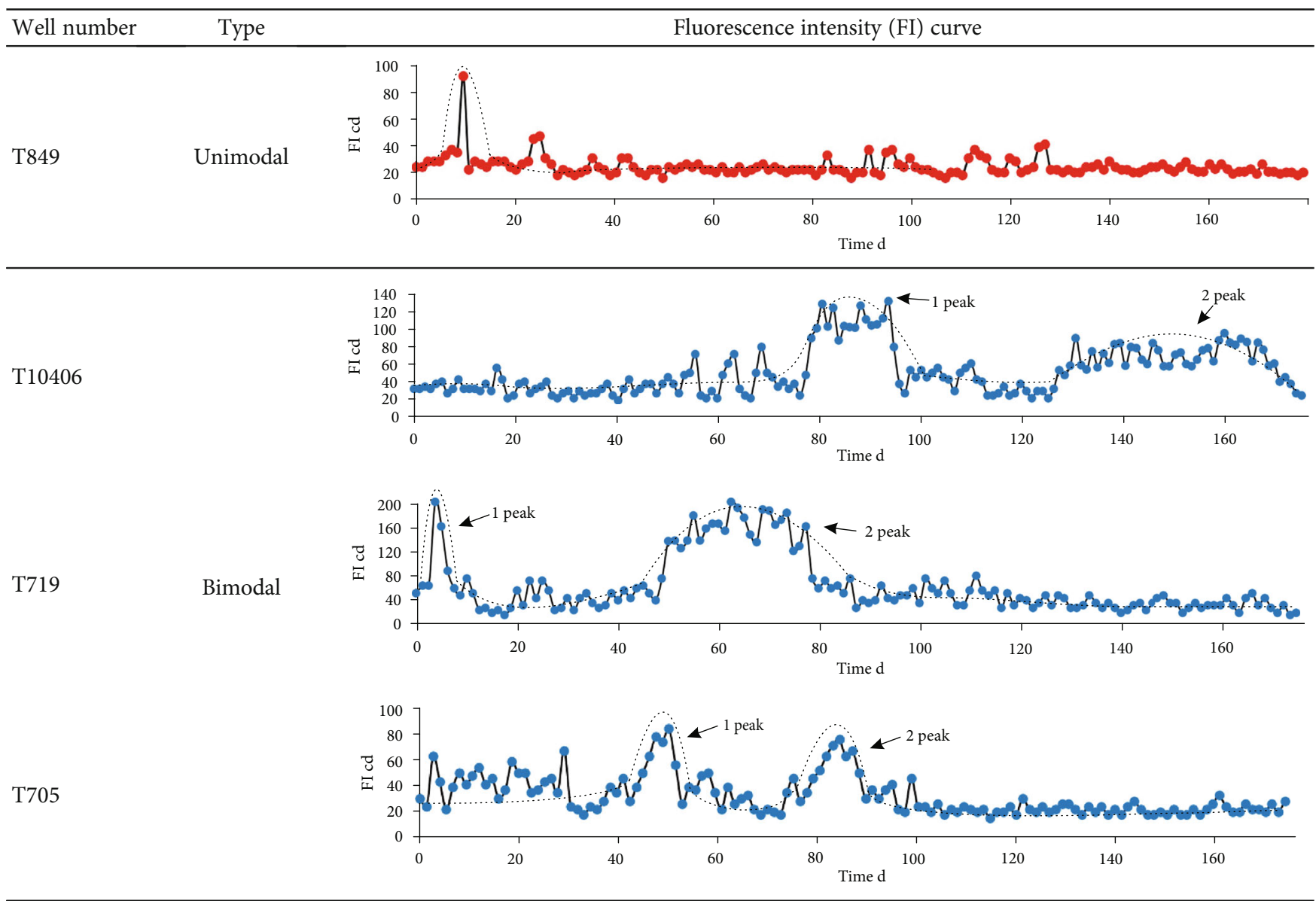

T10263

Multimodal

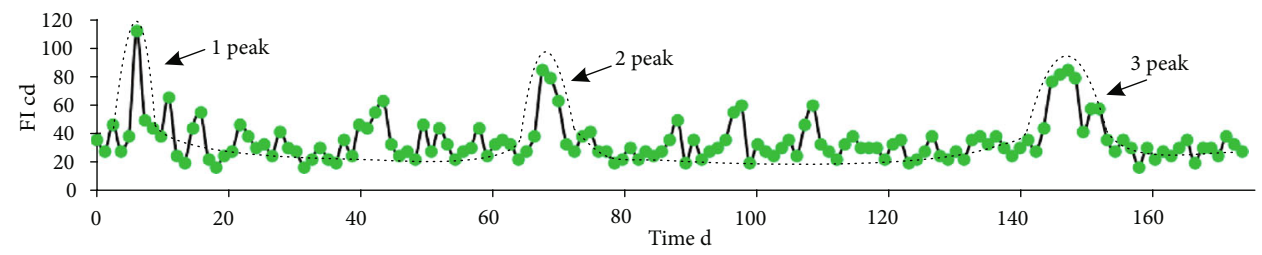

T847

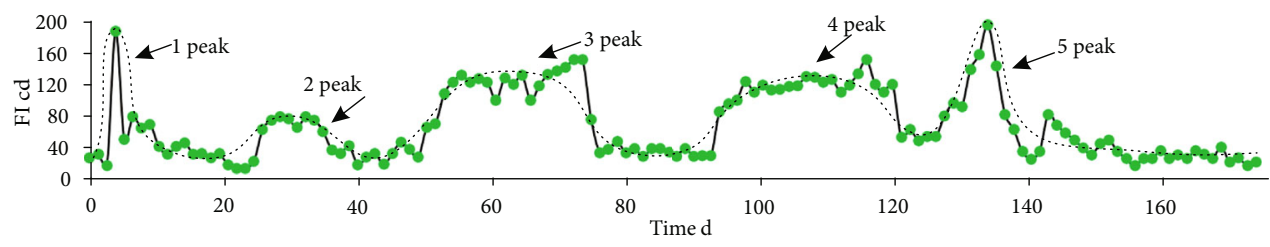

following conclusions can be drawn: tracer fluorescence intensity curve (proportional to the concentration curve, for the convenience of analysis, only the concentration curve will be mentioned below) of Well T849 shows that there is only a single small-volume connected channel with poor conductivity between injection and production wells. There are two large-volume connecting channels between injection and production wells in Well T10406, but the concentration of the tracer produced is not high, which means that the channel has a general conductivity. There are two connecting channels with a large difference in conductivity between the wells of Well T719, and their volumes are also greatly differ- ent. Tracer production concentration performance is good, and the channel conductivity is strong. There are two small-volume connecting channels between the injection and production wells in Well T705. The tracer concentration curve of Well T10263 was of the multipeak type, which showed that there were three small connected channels with similar conductivity between injection and production wells. Well T847 was characterized by the coexistence of three large-volume and several small-volume connected channels.

According to the tracer monitoring response data, the propulsion velocity is calculated by the interval between each well and the regional structure diagram; a waterline propulsion 


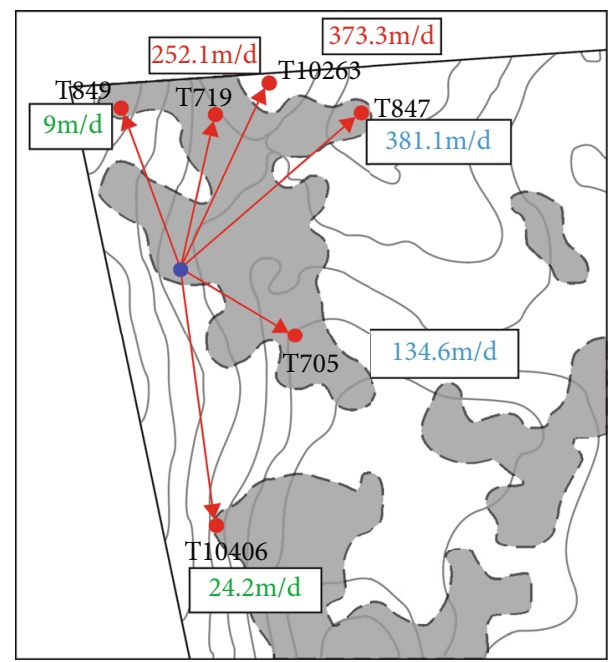

FIgURE 9: Waterline propulsion velocity diagram of T-Well Group. The blue dot represents injection well and the red dots represent production wells.

velocity diagram is drawn as shown in Figure 9. This figure is consistent with the above analysis results, indicating that the results of the peak type classification are reliable and in line with the actual situation.

\section{Discussions and Conclusions}

The tracer monitoring technology is simpler, more intuitive, and easier to operate than other technologies for evaluating interwell connectivity. To conduct a more detailed study on the tracer monitoring results, based on the CFD method, FEM software was used as a CFD simulation tool to discuss and classify the law of tracer concentration curve according to different fracture-vuggy structure modes. The example T-Well Group also verified the research results. Specifically, the following conclusions were reached:

(1) Some physical parameters of the model will have an impact on the concentration of tracer, which is shown in the following aspects: when the flow velocity of the fluid passing through the connected channel decreases, the diameter and length of the connected channel increase; the tracer concentration changes with a decreasing trend. Moreover, the flow velocity and the length of the connected channel also affect the breakthrough time of the tracer concentration curve

(2) Different connectivity models are established by software. According to the simulation, the tracer concentration curve can be classified into three types: unimodal curve, bimodal curve, and multimodal curve

(i) The unimodal curve represents a single interwell connecting channel, and the small or large channel volume determines the steepness or gentleness of the single-peak curve of the tracer concentration (ii) The bimodal curve represents two interwell connecting channels, and the volume of the channel determines the peak value of the tracer concentration curve

(iii) The multimodal curve represents multiple interwell connecting channels, which may be more of a combination mode with the coexistence of large and small connected channels. The size of the channel volume determines the time and height of the peak of the tracer concentration

(3) To further verify the classification results of the connected channels, a field example of the T-Well Group in the Tahe Oilfield was discussed. After sorting and summarizing the data, the tracer concentration curves obtained from 6 wells in the Tahe TWell Group can be divided into three categories: unimodal type, bimodal type, and multimodal type. It can be concluded that the connecting channels of T849, T10406, and T705 are not strong in conductivity. The connecting channels of T719, T10263, and T847 have relatively strong flow conductivity. The comparison between the waterline propulsive velocity diagram and the above analysis results shows that the peak type classification results are reliable and in line with the actual situation

(4) The model established in this paper is just a basic simple model. Therefore, to have a more comprehensive and in-depth understanding of fluid migration in the complex interwell connected channels in the carbonate reservoirs, further and deeper studies on this part should be made in the future

\section{Data Availability}

The data used to support the findings of this study are included within the article.

\section{Conflicts of Interest}

The authors declare that they have no conflicts of interest.

\section{Acknowledgments}

This research is supported by the National Natural Science Foundation of China (No. 51904254) and Science and Technology Cooperation Project of the CNPC-SWPU Innovation Alliance (No. 2020CX030200). The authors are thankful for all of the support for this basic research.

\section{References}

[1] G. Q. Zhang and L. D. Mi, "Sedimentary facies of clasticplatform carbonate sediment strata of epicontinental sea in the Daniudi Gasfield, Ordos Basin," Natural Gas Industry B, vol. 8, no. 3, pp. 239-251, 2021.

[2] Z. Tariq, M. Mahmoud, H. Al-Youssef, and M. R. Khan, "Carbonate rocks resistivity determination using dual and triple 
porosity conductivity models," Petroleum, vol. 6, no. 1, pp. 35$42,2020$.

[3] X. Wang, C. Chen, X. Han et al., "A new model to infer interwell connectivity in low permeability oil field," in SPE/IATMI Asia Pacific Oil \& Gas Conference and Exhibition, p. 11, Bali, Indonesia, 2019.

[4] Z. Yin, C. MacBeth, R. Chassagne, and O. Vazquez, "Evaluation of inter-well connectivity using well fluctuations and 4D seismic data," Journal of Petroleum Science and Engineering, vol. 145, pp. 533-547, 2016.

[5] W. Zhigang, Z. Dan, L. Yuquan, and Z. Guorong, "Oil layer connectivity in the sixth block of Gudong oilfield, the evidence from gas chromatography fingerprint technique," Petroleum Exploration and Development, vol. 31, pp. 82-83, 2004.

[6] P. C. Smalley, A. Lønøy, and A. Raheim, "Spatial ${ }^{87} \mathrm{Sr} /{ }^{86} \mathrm{Sr}$ variations in formation water and calcite from the Ekofisk chalk oil field: implications for reservoir connectivity and fluid composition," Applied Geochemistry, vol. 7, no. 4, pp. 341-350, 1992.

[7] C. R. Johnson, R. A. Greenkorn, and E. G. Woods, "Pulse-testing: a new method for describing reservoir flow properties between wells," Journal of Petroleum Technology, vol. 18, no. 12, pp. 1599-1604, 1966.

[8] W. B. Du, J. G. Zhang, and S. Z. Hao, "The application of pulse well tests for the well group of forerunner test of tertiary oil recovery in Yumen oilfield," Well Testing, vol. 11, pp. 32-33, 2002.

[9] A. Kumar, P. Seth, K. Shrivastava, R. Manchanda, and M. M. Sharma, "Integrated analysis of tracer and pressureinterference tests to identify well interference," SPE Journal, vol. 25, no. 4, pp. 1623-1635, 2020.

[10] F. E. Jansen and M. G. Kelkar, "Non-stationary estimation of reservoir properties using production data," in SPE Annual Technical Conference and Exhibition, p. 8, San Antonio, Texas, 1997.

[11] K. J. Heffer, R. J. Fox, C. A. McGill, and N. C. Koutsabeloulis, "Novel techniques show links between reservoir flow directionality, earth stress, fault structure and geomechanical changes in mature waterfloods," Society of Petroleum Engineers Journal, vol. 2, pp. 91-98, 1997.

[12] A. Albertoni and L. W. Lake, "Inferring interwell connectivity only from well-rate fluctuations in waterfloods," SPE Reservoir Evaluation \& Engineering, vol. 6, no. 1, pp. 6-16, 2003.

[13] P. H. Gentil, The Use of Multilinear Regression Models in Patterned Waterfloods: Physical Meaning of the Regression Coefficients, The University of Texas, Austin, 2005.

[14] D. Kaviani, P. P. Valkó, and J. L. Jensen, "Application of the multiwell productivity index-based method to evaluate interwell connectivity," in SPE Improved Oil Recovery Symposium, p. 18, Tulsa, Oklahoma, USA, 2010.

[15] P. Lerlertpakdee, B. Jafarpour, and E. Gildin, "Efficient production optimization with flow-network models," Society of Petroleum Engineers Journal, vol. 19, pp. 1083-1098, 2014.

[16] A. A. Yousef, P. H. Gentil, J. L. Jensen, and L. W. Lake, “A capacitance model to infer Interwell connectivity from production and injection rate fluctuations," SPE Reservoir Evaluation \& Engineering, vol. 9, no. 6, pp. 630-646, 2006.

[17] A. A. Yousef, L. W. Lake, and J. L. Jensen, “Analysis and interpretation of interwell connectivity from production and injection rate fluctuations using a capacitance model," in SPE/DOE
Symposium on Improved Oil Recovery, p. 15, Tulsa, Oklahoma, USA, 2006.

[18] M. Sayarpour, E. Zuluaga, C. S. Kabir, and L. W. Lake, "The use of capacitance-resistive models for rapid estimation of waterflood performance," in SPE Annual Technical Conference and Exhibition, p. 13, Anaheim, California, USA, 2007.

[19] G. A. Moreno, "Multilayer capacitance-resistance model with dynamic connectivities," Journal of Petroleum Science and Engineering, vol. 109, pp. 298-307, 2013.

[20] A. Mamghaderi and P. Pourafshary, "Water flooding performance prediction in layered reservoirs using improved capacitance-resistive model," Journal of Petroleum Science and Engineering, vol. 108, pp. 107-117, 2013.

[21] Z. Q. Zhang, H. Li, and D. X. Zhang, "Water flooding performance prediction by multi-layer capacitance-resistive models combined with the ensemble Kalman filter," Journal of Petroleum Science and Engineering, vol. 127, pp. 1-19, 2015.

[22] R. W. Holanda, E. Gildin, and J. L. Jensen, "Improved waterflood analysis using the capacitance-resistance model within a control systems framework," in SPE Latin American and Caribbean Petroleum Engineering Conference, p. 38, Quito, Ecuador, 2015.

[23] Z. Zhang, M. Q. Chen, and Y. L. Gao, "Estimation of the connectivity between oil wells and water injection wells in lowpermeability reservoir using tracer detection technique," Journal of Xi'an Shiyou University (Naturnal Science Edition), vol. 21, pp. 48-51, 2006.

[24] H. Zhao, Y. Li, S. Cui et al., "History matching and production optimization of water flooding based on a data-driven interwell numerical simulation model," Journal of Natural Gas Science and Engineering, vol. 31, pp. 48-66, 2016.

[25] X. Huang and Y. Ling, "Water injection optimization using historical production and seismic data," in SPE Annual Technical Conference and Exhibition, p. 8, San Antonio, Texas, USA, 2006.

[26] D. A. Hutchinson, N. Kuramshina, A. C. Sheydayev, and S. N. Day, "The new interference test: reservoir connectivity information from downhole temperature data," in International Petroleum Technology Conference, p. 13, Dubai, UAE, 2007.

[27] M. N. Panda and A. K. Chopra, "An integrated approach to estimate well interactions," in SPE India Oil and Gas Conference and Exhibition, p. 14, New Delhi, India, 1998.

[28] W. E. Brigham and A. Maghsood, "Tracer testing for reservoir description," Journal of Petroleum Technology, vol. 39, no. 5, pp. 519-527, 1987.

[29] V. A. Morales, L. K. Ramirez, S. V. Garnica et al., "Inter well tracer test results in the mature oil field La Cira Infantas," in SPE Improved Oil Recovery Conference, p. 22, Tulsa, Oklahoma, USA, 2018.

[30] A. Al-Qasim, S. Kokal, S. Hartvig, and O. Huseby, "Subsurface monitoring and surveillance using inter-well gas tracers," Upstream Oil and Gas Technology, vol. 3, p. 100006, 2020.

[31] A. Al-Qasim, S. Kokal, S. Hartvig, and O. Huseby, "Reservoir description insights from inter-well gas tracer test," in $\mathrm{Abu}$ Dhabi International Petroleum Exhibition \& Conference, p. 13, Abu Dhabi, UAE, 2019.

[32] M. Sanni, M. Abbad, S. Kokal et al., "A field case study of an interwell gas tracer test for GAS-EOR monitoring," in $\mathrm{Abu}$ Dhabi International Petroleum Exhibition \& Conference, p. 10, Abu Dhabi, UAE, 2017. 
[33] M. T. Al-Murayri, A. Al-Qenae, D. Al Rukaibi, M. Chatterjee, and P. Hewitt, "Design of a partitioning interwell tracer test for a chemical EOR pilot targeting the Sabriyah Mauddud carbonate reservoir in Kuwait," in SPE Kuwait Oil \& Gas Show and Conference, p. 9, Kuwait, 2017.

[34] L. Jain, T. Zhang, H. Nguyen et al., "Waterflood conformance improvement method in naturally fractured carbonate reservoirs with gel injection," in International Petroleum Technology Conference, p. 14, Dhahran, Kingdom of Saudi Arabia, 2020.

[35] L. Konwar, E. Al Owainati, N. Nemmawi, D. Michael, and A. Ali, "Understanding Mauddud waterflood performance in a heterogeneous carbonate reservoir with surveillance data and ensemble of analytical tools," in Abu Dhabi International Petroleum Exhibition \& Conference, p. 23, Abu Dhabi, UAE, 2020.

[36] S. Tran, A. Habibi, H. Dehghanpour, M. Hazelton, and J. Rose, "Leakoff and flowback experiments on tight carbonate core plugs," SPE Drilling \& Completion, vol. 36, pp. 150-163, 2020.

[37] J. Hagoort, "The response of interwell tracer tests in wateredout reservoirs," in SPE Annual Technical Conference and Exhibition, p. 21, New Orleans, Louisiana, 1982.

[38] L. Zhang, J. Mou, X. Cheng, and S. Zhang, "Evaluation of ceramsite loss control agent in acid fracturing of naturally fractured carbonate reservoir," Natural Gas Industry B, vol. 8, no. 3, pp. 302-308, 2021.

[39] H. Sun, X. YanMei, H. Jianfa, S. Ying, L. Linlin, and C. Wen, "Integrating geological characterization and historical production analysis to evaluate interwell connectivity in Tazhong1 Ordovician carbonate gas field, Tarim basin," in SPE EUROPEC/EAGE Annual Conference and Exhibition, p. 8, Vienna, Austria, 2011.

[40] W. Wang, J. Yao, Y. Li, and A. Lv, "Research on carbonate reservoir interwell connectivity based on a modified diffusivity filter model," Open Physics, vol. 15, pp. 306-312, 2017.

[41] W. E. Brigham, P. W. Reed, and J. N. Dew, "Experiments on mixing during miscible displacement in porous media," Society of Petroleum Engineers Journal, vol. 1, no. 1, pp. 1-8, 1961.

[42] C. Hirsch, Numerical Computation of Internal and External Flows: The Fundamentals of Computational Fluid Dynamics, Butterworth-Heinemar, 2007.

[43] S. V. Patankar and D. B. Spalding, "Расчет переноса тепла, массы и импульа в тречмерныч параболическич потокач," International Journal of Heat and Mass Transfer, vol. 15, no. 10, pp. 1787-1806, 1972. 